\title{
Paideusis
}

\section{Rationality and Intuition}

\section{Sharon Bailin}

Volume 4, Number 2, 1991

URI: https://id.erudit.org/iderudit/1073380ar

DOI: https://doi.org/10.7202/1073380ar

See table of contents

Publisher(s)

Canadian Philosophy of Education Society

ISSN

0838-4517 (print)

1916-0348 (digital)

Explore this journal

Cite this article

Bailin, S. (1991). Rationality and Intuition. Paideusis, 4(2), 17-26.

https://doi.org/10.7202/1073380ar

This document is protected by copyright law. Use of the services of Erudit (including reproduction) is subject to its terms and conditions, which can be viewed online.

https://apropos.erudit.org/en/users/policy-on-use/
This article is disseminated and preserved by Érudit.

Érudit is a non-profit inter-university consortium of the Université de Montréal, Université Laval, and the Université du Québec à Montréal. Its mission is to promote and disseminate research.

https://www.erudit.org/en/ 


\section{Rationality and Intuition}

\section{Sharon Bailin, University of Manitoba}

In discussions of creativity, problem-solving and cognitive processes, intuition is often considered a central aspect, and intuition is generally set up in opposition to reason. Cappon, for example, in describing his $\$ 200,000$ study on the use of intuition versus scientific approaches in research, characterizes intuition as follows:

the mental faculty or 'gut feeling' that provides the answer to a problem or propels one to make a decision without going through the process of logical reasoning. ${ }^{1}$

Cappon, who recommends intuition as an important means to solve problems, contrasts those who use intuition with those who "think logically, rationally, and deductively to prove how things work or should be done," and also sets intuition in contrast to logic, intelligence, and scientific technologies. This type of view is extremely common in the literature. This is but one example, though a particularly striking one.

If the outcomes attributed to intuition are deemed educationally valuable, then this opposition between rationality and intuition could have important educational implications. In this paper, I argue that this opposition is problematic, resting on a false dichotomy between reasoning and creative thinking, a misunderstanding of skills and rules, an excessively narrow concept of rationality, and a false opposition between reason and emotion. I suggest that intuition, in any sense which is educationally relevant, involves both rational processes which have been mastered and assimilated and the emotional cues which accompany these processes.

\section{The Concept of Intuition}

"Intuition" is a term which can have a variety of meanings and is often applied to a range of apparently disparate cases. A taxonomy provided by Agyakwa ${ }^{2}$ may be of help in clarifying the various meanings. He delineates four different cases of intuitive knowledge. The first is a kind of intuitive insight which would fall within extrasensory perception and would include precognition, telepathy, and clairvoyance. The second type involves the apprehension of self-evident truths involving abstract logical and arithmetical or geometrical principles. The third involves the direct grasp of certain states of affairs, for example, intuitive insights in the aesthetic and moral domains. .The fourth case is that of the insight of the expert who goes straight to the heart of a problem without explicit rational deliberation.

What all these cases have in common, according to Agyakwa, is that they involve immediate apprehension -- that is, an awareness of reality or a state of affairs that is unmediated by inference, causes, ability to define, or justification. This immediate apprehension is, for Agyakwa, the defining characteristic of intuition, and this is a notion that runs through many conceptions of intuition. Noddings, for example, views intuition as a kind of unreflective consciousness which involves direct contact with objects rather than conventional rational processes. ${ }^{3}$ Kautz sees it as the human ability of direct knowing or acquiring knowledge without rational thought. ${ }^{4}$ And Bruner defines intuition as "the act 
of grasping the meaning or significance or structure of a problem without explicit reliance on the analytic apparatus of one's craft." 5 The apparent absence of conscious rational deliberation is one important feature of all these views of intuition. The powerful emotional concomitant to the intuitive process is another.

Viewing all the cases listed above as instances of the same phenomenon seems to rest on the assumption of a human faculty of intuition, or at least of a process or mode of knowing which is distinguishable from rational modes of cognition. The problems of faculty psychology require no further elaboration here. The claim that these cases exemplify a distinctive non-rational process is the main point at issue. But it is also important to see which cases are relevant in terms of our educational concerns.

The first case of intuition as extrasensory perception involves ideas whose origins defy causal explanation. In this sense, intuition is by definition irrational. This is not the sense of intuition which is of interest to Cappon, however. He explicitly states that "intuition is not clairvoyance or seeing things or ESP or coincidence or luck or guesswork." Moreover, any concept of intuition involving phenomena which lie outside the realm of understandable causal connections is of very little use for educational purposes.

The second case of intuition, that of apprehending self-evident truths, has some plausibility as an instance of immediate apprehension. It could well be argued that we just see the truths of logic in some direct way. Yet in this case, intuition is clearly not in opposition to rationality. Rather, it is what makes rationality possible. Moreover, this ability to apprehend self-evident truths is something we presumably all inherently possess and, thus, would not be a focus of educational efforts.

The third sense of intuition involves direct insights, particularly in the aesthetic and moral domains. Agyakwa's claim is that human beings have the possibility of direct intuitive access to aesthetic understanding, moral values, and other types of insights unmediated by rational analysis. He gives, as examples, the direct comprehension of aesthetic objects and the intuition involved in romantic attraction, stating of the latter that "Sweethearts and friends are not chosen on the basis of empirical analysis, e.g., by considering the vital statistics." 6 This type of case does seem to be an initially plausible candidate for apprehension unmediated by rationality, and one which might be important educationally. Thus, this is a case to which we shall return.

It is the fourth case, however, that of the intuition of the expert, which is of central interest here. Intuition in this sense refers to those occasions when one solves a problem with seeming effortlessness, without consciously thinking through each of the steps of the solution -- when the answer seems to come out of nowhere. It applies to those cases when one feels one knows a solution or direction for investigation without being able to articulate the reasons. This is the kind of intuition which Cappon has in mind when he refers to "the mental faculty or 'gut feeling' that provides the answer to a problem or propels one to make a decision without going through the process of logical reasoning." And it is precisely this claim, that intuition, in this sense, does not involve reasoning, which will be examined here.

Before investigating this claim, however, it is important to distinguish between successful and unsuccessful intuition. Certainly one may be led to the 
solution to a problem through an intuitive sense of where the solution lies. One may have a feeling or idea which seems to come out of nowhere and which results in successful creation. Yet clearly the opposite is also possible. We can certainly imagine the artist who, in a flash, get an idea for a painting which results in a bad painting, or a scientist whose intuited idea for the solution to a problem simply does not work. That an idea arises from intuition is no guarantee of its quality; ideas which seem to come out of nowhere may well lead nowhere. Intuition is not, then, a reliable guide to successful creation or discovery. Thus, what is of interest are those cases where intuition does lead to successful problem-solving. In such cases, is intuition non-rational?

\section{Critical and Creative Thinking}

The strongest version of the non-rationality claim is that intuition is, in fact, irrational. Intuition is believed to be a process which is central to creativity and the irrationality thesis is based on the view that all creative processes are necessarily irrational. According to this view, creativity involves the breaking of rules and the transcending of frameworks. Logical, rational thinking can only be used to arrive at assessments within the confines of the prevailing framework but, since it is circumscribed by the logic of the framework, it cannot provide the means to transcend the framework itself.

Creative processes, on the other hand, because they involve breaking out of old frameworks, are thought to require defiance of the logic of the framework and are, thus, seen as necessarily irrational. Intuition would be a prime example of such a process. A good statement of this view of creative processes as non-rational is given by Koestler as follows:

The creative act, in so far as it depends on unconscious resources, presupposes a relaxing of the controls and a regression to modes of ideation which are indifferent to the rules of verbal logic, unperturbed by contradiction, untouched by the dogmas and taboos of so-called common sense. ${ }^{7}$

I have argued elsewhere that this characterization of creative processes as necessarily irrational is mistaken. ${ }^{8}$ There are not two distinctive and opposite kinds of processes of thinking, one kind irrational and leading to creative achievement and the other kind rational and involved in the evaluation of ideas or products. Rather, there are analytic, highly judgmental aspects to generating creative results and imaginative, inventive aspects to logic and reasoning and it is exceedingly difficult to separate two distinct and opposite kinds of thought. An underlying reason for this opposition between creativity and rationality is the view that reasoning always takes place within rigidly bounded and highly rulegoverned frameworks. This view of how frameworks operate is radically defective, however, because frameworks are less definite and more fluid than this view would suggest. Equally mistaken is the view upon which the fixed framework view rests, namely the notion that created works involve a radical break with the past and a discontinuity with the preceding tradition. If this reasoning is correct, then there is no reason to posit non-rational non-evaluative processes of thinking which break all the rules in order to transcend a framework. There is no reason to believe that intuition, as a creative process, is irrational. 


\section{Rationality and Skills}

The weaker version of the non-rationality thesis is that intuition, although not necessarily irrational, is a-rational -- that is, it does not involve rational processes. One of the primary reasons for this claim is the apparent absence of conscious deliberation in arriving at solutions to problems. I would maintain, however, that the absence of explicit conscious deliberation does not indicate that a process is not reasonable or rational. This becomes apparent if one examines closely the process involved in acquiring skill at solving problems in any area. When one first learns a skill, each application involves conscious and often painstaking deliberation. One must go through each step of the deliberative process and see how what has been learned applies in the particular case. Step-by-step, explicit reasoning is required. As one becomes more skilful, however, the skills become assimilated and operate below the level of conscious awareness. Less explicit deliberation is required. A true expert in a field is able to go right to the solution without explicitly going through each of the steps. Nonetheless, there is no reason to assert that a different process is involved. The expert does not suddenly, at some stage of the learning process, begin to deploy non-rational processes. Rather, the processes are executed with great speed. The ability to short-cut the deliberative process, to solve problems with speed and seeming effortlessness, to have a feel for how to solve a problem are all products of expertise, of mastery of the relevant skills and rational processes, of highly developed judgment. ${ }^{9}$

Let us take as an example the activity of doing philosophy. In analyzing an argument, a novice philosophy student will have to consciously rehearse all the potential fallacies and look carefully to see if each one applies in order to find a problem in an argument. A skilled philosopher, however, will look at the argument and immediately understand that something is wrong and have a sense of where the problem lies. She will not have to consciously, systematically, and painstakingly rehearse all possible objections but will go right to the answer. This does not appear to be a process of step by step conscious deliberation. Rather, she solves the problem with seeming effortlessness without consciously thinking through each of the steps of the solution; she has a feeling as to where to look for the solution. This case seems to exhibit the features of intuition. Yet, if we insist on seeing this process as non-rational, then we are led to the surprising conclusion that it is only the novice who consciously goes through each of the steps of reasoning who is being rational. The experience and knowledgeable expert who is able to go straight to the answer or who knows where to look for the answer is not being rational.

\section{Rationality and Conscious Deliberation}

This counter-intuitive result points to the fact that there is something problematic about the conception of rationality which grounds this view. It assumes that rationality requires sequential, systematic, and explicit logical deliberations, and so assimilated processes of thought cannot be rational. I would maintain, however, that to deny rationality to these processes is to adopt an excessively narrow conception of rationality. Much of our thinking is not 
explicit but takes place below the level of conscious awareness. As we master certain skills and techniques, our conscious attention is less and less required for their execution, and we are freed to concentrate explicitly on acquiring new skills and on applying those skills we have mastered in new and more complex contexts. Indeed, little productive thought would be possible if this were not the case. If conscious attention were required for every step in our reasoning, we would be overwhelmed by the demands of the simplest problem. Moreover, it is the ability to execute lower order skills quickly and efficiently which allows the expert to go on to deal with complex and difficult problems. A requirement of conscious and explicit rehearsal of each and every step of reasoning would mean that no one would ever get past the novice state. It would also mean that very little of our thinking would qualify as rational.

Moreover, the lack of explicit awareness does not render processes totally automatic nor preclude the possibility of control. According to Howard,

even as whole aspects of performance become routine, one's articulate awareness continues to range over the activities involved, correcting errors and noting improvements as they occur. ${ }^{10}$

The view that rationality necessarily involves explicit deliberation also imposes an unrealistic temporal requirement on reasoning and ignores the fact that much of our reasoning takes place quickly. Perkins, for example, in his study of individuals engaged in creative endeavours, has shown that the feeling of sudden enlightenment which often accompanies an "insight" solution to a problem does not indicate that reasoning has been by-passed, because reason itself can be either slow and deliberate or quick and spontaneous. ${ }^{11}$ In one of his examples, individuals were faced with a puzzle, the solution to which involved recognizing an anomaly in coin dated 544 B.C. Some of the subjects deliberated at length over the possible problem in the situation, recognized that it concerned the coin, pondered as to possible problems with the coin, realized that the problem had to do with the date, and eventually at some point recognized the anomaly. Other subjects immediately focused on the date and quickly recognized the anomaly. The reaction of others was somewhere in between. There seems no reason to posit fundamentally different types of processes going on with the various subjects. They all used reason to realize that a coin could not bear the date 544 B.C., but some of them did it more quickly than others. The problem-solvers who seemed to be using intuition may simply have been faster reasoners.

An interesting aspect of Perkins' results both with respect to this problem and other studies was that he found very little evidence of pure intuition. Most subjects engaged in some explicit focusing of problems before attaining the "insight", and all made use of previous knowledge and understanding. In fact, most instances of problem-solving seem to display an interplay of moments of intuition and periods of explicit deliberation.

It seems plausible to speculate that one of the factors which contributes to speed in solving problems is exposure to similar problems. When one can recognize a problem as being of a certain type, a schema for solution is more readily at hand. This is, in fact, the finding of Weisberg in his studies of problem-solving. He discovered that the crucial factors which enable individuals to change direction in problem-solving and to attain "insight" solu- 
tions to problems are additional information and experience in solving similar problems. ${ }^{12}$

One might wonder why this picture of a non-rational process involved in solving such problems has any plausibility, and I think that it gains plausibility through analogy with other cases where there appears to be unmediated apprehension. Thus, it might be instructive to return to the third case which Agyakwa describes, namely that of intuitive insights, particularly in the moral and aesthetic spheres. Agyakwa claims that we directly apprehend certain phenomena -- for example, aesthetic objects -- without the intervention of rational analysis. Yet this claim is questionable. Granted that we do not reason our way to aesthetic appreciation by deciding to respond aesthetically based on a rational assessment of the qualities of a work. Nonetheless, our understanding of the qualities of a work does play a role in appreciation in terms of opening up possibilities for response. I may well respond differently to a Bach fugue if I have some understanding of fugue form than if I do not. A similar argument can be made with respect to the example of romantic attraction. Granted that we do not generally fall in love based on a checklist of qualities, and that direct contact with the person is required. Nonetheless, our conceptual understanding of the person's qualities is not totally irrelevant. Thus, we would find it odd if someone viewed another individual as ugly, base, and dull, but nonetheless was romantically attracted to him. We would find it similarly peculiar if one's view of another person as having a remarkable intellect, an irrepressible zest for life, and a devastating smile were totally unconnected with her attraction to him.

It is true that these cases are not examples of syllogistic reasoning, i.e., this musical piece has these features, therefore I will be moved by it, or this person has these qualities, therefore I will be moved by him. They are not examples of deductions, but this does not mean that rationality plays no role.

This point underscores one of the basic problems with the view under discussion, namely, that it misrepresents rationality by equating it with deductive reasoning. The view implies that logical thought can only manipulate elements within a given framework, but cannot go beyond the elements or transcend the framework. A statement of this view is given by de Bono as follows:

Logical thinking can never lead to that alternation of sequence that leads to the "insight" rearrangement of information ... Logical thinking may find out the best way of putting together $A, B$, and C but it will not discover that $A, B$, and $C$ are inappropriate units anyway. ${ }^{13}$

Deductive reasoning represents only a narrow subset of rational thought, however. Logical reasoning also encompasses inductive reasoning, probabilistic reasoning, and analogical reasoning -- none of which is purely deductive. Scientific thought, for example, adds new knowledge to the world and is not purely deductive in nature and yet science is a rational activity. And, as has been pointed out previously, critical, logical thought does have a generative component. It may involve generating counterexamples, comparing an argument to alternatives and questioning assumptions, and so in de Bono's example, logical reasoning may well lead one to conclude that $A, B$, and $C$ are inappropriate units anyway. The realm of rational thought and action is far from circumscribed by deductive logic. 
This equation of rationality with deduction is indicative of the narrowness of the conception of rationality which underpins the view in question. According to this view, rationality consists in reasoning in which the process and outcomes are determined by the rules of logic; that is, reasoning takes place according to algorithms and where logic uniquely determines the solution. This equating of rationality with algorithmic thinking is, in fact, quite common in the literature on intuition, ${ }^{14}$ but is quite misleading. According to this picture, very little thinking other than formal deduction and, perhaps, some mathematical cases would qualify as rational. Most thinking does not involve moving inexorably toward a predetermined solution according to fixed steps. Questions of interpretation and judgment come in at every step of the process. ${ }^{15}$ Consequently, there may be several rational solutions to a problem and numerous paths to rational solutions. Rational people may disagree. Therefore, it may be more accurate to view reason as providing rules which constrain thinking rather than rules which uniquely determine outcomes. The opposition between intuition and rationality depends for its plausibility on a view of rationality which is inaccurate and considerably impoverished.

\section{Reason and Emotion}

The opposition between intuition and rationality also rests on a misleading opposition between reason and emotion. The fact that intuition involves an emotional dimension or "gut feeling" is used as a basis for viewing it as non-rational, yet this is an unwarranted assumption. Reason and emotion are not necessarily opposed one to another, but are, in fact, closely intertwined. Emotions play an important role in cognition in a number of ways. First, reasoned assessments are at the basis of many emotions. We experience fear because we judge a certain set of circumstances to be dangerous. Moreover, cognition is necessarily suffused with emotion, providing cues for further thought and action. Scheffler puts the point as follows:

the emotions intimately mesh with all critical appraisals of the environment:

The flow of feeling thus provides us with a continuous stream of cues significant for orientation to our changing contexts. ${ }^{16}$

Thus, emotions play a role in perception and are often centrally involved in our critical appraisals of situations and in our selection and application of ideas as well as their generation. Certain emotions can become connected with rational assessments and, so, provide the basis for future assessments. ${ }^{17}$ Thus, we may experience fear upon encountering a situation which is similar to one which has been assessed as dangerous in the past even before having the opportunity to fully assess the present situation. And this may be useful, as taking precautionary measures may have more survival value than taking the time to make a full rational assessment. As Goodman says,

In daily life, classification of things by feeling is often more vital than classification by other properties: we are likely to be better off if we are skilled in fearing, wanting, braving, or distrusting the right things, animate or inanimate, than if we perceive only their shapes, sizes, weights, etc. ${ }^{18}$

The emotion provides a useful shorthand, directing our attention and defining salient features in experience. ${ }^{19}$ Nonetheless, the assessment implicit in the emotion would need ultimately to be verified against experience. The new 
experience may turn out to be unlike the first experience in some important way and, thus, not dangerous. Or, we may be paranoid and have a tendency to experience fear which is only minimally grounded in rational assessments. The emotion may be a useful guide to thought and action, though not an infallible one.

The situation seems to be parallel in the case of the feeling which is central to intuition. We may have an intuition to investigate in a certain direction for a solution to a problem without any explicit awareness of the judgments underlying this feeling. Yet, the emotion may be connected with previous successful assessments and a recognition of similarity between this and other past problems. This intuitive feeling is a product of knowledge, experience and a high level of assimilated skill and judgment. As in the case of fear, however, the feeling may turn out to be ungrounded. The present problem may turn out to be unlike the past problems in some important way, and the intuitive feeling may lead nowhere. Or, it may be that an individual is prone to intuitions which tend to be grounded only minimally in rational assessments and generally turn out to be bad ideas. Intuitions are a useful, but not an infallible guide to solving problems.

\section{Conclusion}

What can be concluded about intuition and its role in education? We have already seen that the first two senses of intuition outlined in the taxonomy are not particularly relevant to educational practice. With respect to the third sense, I have tried to show that, although direct encounter with objects of intuition is necessary, what we draw from this encounter is a product, to some extent at least, of our conceptual understanding. Thus, there is doubtless merit in Noddings' views regarding the importance of receptivity and emotion engagement with objects of knowledge (with works of art, with academic concepts, with people). Nonetheless, knowledge and rational understanding are necessary in order for such an encounter to be productive. Thus, this view reinforces rather than minimizes the importance of the enhancement of such understanding.

As to the fourth sense, the phenomenon pointed to does seem to be real, i.e., we do sometimes have a feeling that propels us to investigate in a certain direction or to make a decision without being aware of the reasons or consciously thinking through each step of the reasoning. But it seems clear that this type of feeling is not always reliable. An intuition does not always lead to the solution to a problem, and ultimately the idea must be tested and verified through experience and explicit argumentation. There is no reason to believe that intuition provides any privileged access to sound ideas or creative solutions to problems. Thus, I am not advocating that we urge students to ignore their intuitions, but rather that we impress on them the need for such intuition to be verified.

Even in cases of successful intuition, however, I have argued that it is a mistake to set intuition in opposition to reason. The arguments for the necessarily non-rational character of creative processes are unfounded, and the phenomenon of successful intuition can be explained in terms of the assimilation of rational processes and the emotional cues which mark these processes.

If intuition were non-rational, then in order to foster it, one would have to suspend or downplay rationality. Thus, Cappon complains that we tend to pay 
too much attention to logic, intelligence, and scientific method and makes the following recommendation for developing intuition: "Put yourself in a reverie, a sort of twilight, and think diffusely. Let ideas strike you instead of pursuing them." And Agyakwa recommends that we put less emphasis on asking students for reasons, explanations and justification, and that we accept their intuitions as a valid source of knowledge.

The rejection of the intuition-rationality opposition puts such pedagogical recommendations into question, however. They tend to mischaracterize rationality as algorithmic. Noddings even goes so far as to contrast intuitive modes of teaching, which are those which engage students affectively, with analytic modes which are identified with algorithmic calculation, with filling in blanks on work sheets, and with stultifying classroom rituals. Certainly, an emphasis on rationality does not imply routine performance, nor does it preclude affective engagement with the material studies.

If intuition in the sense at issue here really refers to the kind of insight possessed by the expert, then my recommendation would be to attempt to develop a level of expertise in students and, thus, to promote the critical thought, the experience with a wide range of problems, and the knowledge and understanding in the disciplines which make such insight possible.

As to the mode of receptivity which is claimed to be necessary for intuition, I would fully concur with the idea that we should encourage students to be receptive to new ideas, to engage fully and affectively with the materials of study and with the process of inquiry. There is, however, a danger in confusing receptivity with passivity, and, thus, of avoiding the struggle inherent in inquiry in the name of waiting for the muse to strike. Certainly students should understand that they may need quiet time to think, and that it may be helpful to get some distance on a problem. But, rather than encouraging students to wait passively for intuition to strike, we would do better to encourage their emotional engagement with critical inquiry and their active pursuit of understanding and enlightenment. ${ }^{20}$ 


\section{Notes}

${ }^{1}$ Quoted in the Globe and Mail, July 12, 1988.

${ }^{2} \mathrm{~K}$. Agyakwa, "Intuition, Knowledge and Education," Journal of Educational Thought, 22 (3), 1988.

${ }^{3}$ Nel Noddings, Awakening the Inner Eye: Intuition in Education (New York: Teachers College Press, 1984).

${ }^{4}$ Cited in Noddings, 182.

${ }^{5} \mathrm{~J}$. Bruner, On Knowing: Essays for the Left Hand (Cambridge, Mass.: Harvard University Press, 1966), 102.

6Agyakwa, "Intuition, Knowledge and Education," 167.

${ }^{7}$ A. Koestler, The Act of Creation (London: Pan Books, 1985), 178.

${ }^{8}$ S. Bailin, Achieving Extraordinary Ends: An Essay on Creativity (Dordrecht: Kluwer, 1988).

${ }^{9}$ For an elaboration of this skill and its relationship to creativity, see S. Bailin, "Creativity and Skill," in Thinking: The Second International Conference, D. Perkins, J. Lockhead, \& J. Bishop (Eds.) (Hillsdale, N.J.: Erlbaum, 1987), 323-332; Bailin, Achieving Extraordinary Ends. Cf. also M. Polanyi's notion of tacit knowledge in his The Tacit Dimension (New York: Doubleday, 1966). 1982).

${ }^{10}$ V.A. Howard, Artistry: The Work of Artists (Indianapolis: Hackett, Press, 1981).

${ }^{11}$ D. Perkins, The Mind's Best Work (Cambridge: Harvard University

${ }^{12}$ R. Weisberg, Creativity: Genius and Other Myths (New York: W.H. Freeman and Co., 1986).

${ }^{13} \mathrm{E}$. de Bono, The Mechanism of Mind (Middlesex: Penguin Books, 1969), 228.

${ }^{14}$ See, for example, Noddings, Awakening the Inner Eye.

${ }^{15}$ See S. Bailin, "Argument Criticism as Creative," in R. Trapp \& J. Schuetz (Eds.), Perspectives on Argumentation: Essays in Honour of Wayne Brockriede (Prospect Heights, Illinois: Waveland Press, forthcoming).

16. Scheffler, "In Praise of the Cognitive Emotions," in I. Scheffler, Science and Subjectivity (2nd Edition) (Indianapolis: Hackett Publishing Company, 1982), 145.

${ }^{17}$ Ibid.

${ }^{18}$ N. Goodman, Languages of Art (Indianapolis: Hackett Publishing Co., 1976), 251.

${ }^{19} \mathrm{Cf}$. R. de Sousa, The Rationality of Emotion (Cambridge, Mass.: MIT Press, 1987).

${ }^{20} \mathrm{~A}$ previous version of this paper was presented at a meeting of the Far Western Philosophy of Education Society, Calgary, December 1988. I am grateful to Neil Innes, Romulo Magsino, Stuart Richmond, and Harvey Siegel for helpful comments on the earlier paper. 